\title{
Kültür varlıklarının yersel lazer tarama yöntemi ile dijital dokümantasyonu: Zonguldak Uzun Mehmet Anıtı örneği
}

\section{Mustafa Özendi*1}

1Zonguldak Bülent Ecevit Üniversitesi, Mühendislik Fakültesi, Geomatik Mühendisliği Bölümü, Zonguldak, Türkiye

Anahtar Kelimeler

Kültür Varlığı

Yersel Lazer Tarama

3B Yüzey Modeli

3B Yazıcl

\section{ÖZ}

Kültür varlıklarının korunması ve gelecek nesillere aktarılması büyük önem taşımaktadır. Bu aktarım için varlığın dijital dokümantasyonunun yapılmış olması gerekmektedir. Böylece zarar gören kültür varlığının restorasyonu için projelendirme gerçeğe uygun olacaktır. Bu çalışmada Yersel Lazer Tarayıcı (YLT) kullanılarak kültür varlıklarının dijital dokümantasyon adımları detaylı bir şekilde ele alınmıştır. Çalışmada Zonguldak'ta bulunan Uzun Mehmet Anıtı kullanılmıştır. Çalışmada 13 adet tarama gerçekleştirilmiștir. Birleștirme ve hatalı noktaların temizlenmesinden sonra 3 boyutlu (3B) yüzey model olușturulmuștur. Bu yüzey modeli kullanılarak ihtiyaca yönelik olarak uygulamalar yapılmıștır. Projelere temel olmak üzere CAD çizimleri yapılmıştır. Ayrıca 3B yazıcı kullanılarak anıtın ₹1/100 ölçeğinde gerçek modelinin baskısı alınmıștır.

\section{Digital documentation of cultural heritage with terrestrial laser scanning (TLS): The case study of Zonguldak Uzun Mehmet Monument}

\section{Keywords}

Cultural Heritage

Terrestrial Laser Scanning

3D Surface Mesh

3D Printer

\begin{abstract}
It is very significant to protect and hand down cultural heritage to next generations. To be able to accomplish this mission, digital documentation of the cultural heritage should be prepaed. Thus, the project design for the restoration of the damaged cultural heritage will be realistic. In this study, digital documentation steps of the cultural heritage were discussed in detail using the Terrestrial Laser Scanner (TLS). Zonguldak Uzun Mehmet Monument was used as a test object. Totally, 13 scans were acquired in the field. After the registration and elimination of points with gross error, the 3D surface mesh was generated. Various applications were carried out using the 3D surface mesh. For example, CAD drawings were created to be used in various projects and the $\approx 1 / 100$ scale model of the monument was printed using a $3 \mathrm{D}$ printer.
\end{abstract}




\section{GíRiş}

Kadim bir geçmișe sahip olan ülkemiz, tarih sürecinde birçok medeniyetin doğup yok olmasına şahitlik etmiştir. $\mathrm{Bu}$ medeniyetler arkalarında paha biçilemez sayısız eserleri bırakarak tarihteki yerlerini almışlardır. Bu eserlerin kimi tamamen yok olmuş kimi keşfedilerek insanlığın istifadesine sunulmuş kimi de halen bulunduğu yerde keşfedilmeyi beklemektedir. Bu tür keşiflerin sadece sergilenmelerinden daha farklı işlevlerinin olduğu Göbekli Tepe arkeolojik yerleşim alanı örneği ile karşımıza çıkmaktadır. 15.04.2011 tarihinde UNESCO Dünya Mirası Geçici Listesine alınan Göbekli Tepe arkeolojik yerleşim alanı, 1 Temmuz 2018 tarihinde 42. Dünya Mirası Komitesi toplantısında alınan karar ile Dünya Mirası Listesine kaydedilmiştir (Yağmurlu, 2020). Göbekli Tepe'nin keşfi sayesinde insanlığın tarihi ile ilgili şimdiye kadar savunulan pek çok fikirde büyük değişimler olmuştur (Natura, 2019).

Böylesine önemli kültür varlıklarını gelecek nesillere aktarabilmek için dijital dokümantasyonunun yapılması elzemdir. Kültür varlıkları bir şekilde tahrip olduğunda bu dokümantasyon sayesinde restorasyon ve restitüsyonu yapılarak gelecek nesillere aktarılabilir. Bu durumun en güncel örneklerinden biri Fransa'da bulunan Notr-Dam Katedrali'dir. Restorasyon çalışmaları sırasında çıkan yangın ile çok ciddi zarar gören katedral daha önceden yapılan dijital dokümantasyon çalışmaları sayesinde aslına uygun olarak restore edilmektedir (Madrigal, 2019). Bu örnek de kültür varlıklarının dijital dokümantasyonunun ne kadar önemli olduğunu gözler önüne sermektedir.

Kültür varlıklarının dokümantasyonu için kullanılan yöntemler elekro-optik teknolojilerinin gelişmesi ile birlikte kullanılan veri elde etme yöntemine göre çeşitlenmiştir (Gomes ve ark,. 2014; Santos Junior ve ark, 2012). Geçmişte dokümantasyon cetvel, metre ve el çizimleri ile birlikte yapılırken, bugün fotogrametri (Aicardi ve ark., 2018) ve lazer tarama yöntemleri (Akca, 2012; Fryskowska ve ark., 2015) sayesinde daha kısa sürede, daha doğru ve hassas şekilde dijital ortamlarda yapılmaktadır.

Günümüzde Yersel Lazer Tarama (YLT) teknolojisi hem ülkemizde hem de dünyada kültür varlıklarının dijital dokümantasyonu için en yaygın kullanılan yöntemlerden biri olmuştur. Örneğin, Mersin İlindeki Kanlıdivane Ören Yeri içinde bulunan bir anıtmezarın 3B modellemesi YLT kullanılarak yapılmıştır (Alptekin ve ark., 2019a). Benzer çalışma, Adana'nın ören yerlerinden Üçayak ören yerinde bulunan bir çiftlik yapısı için de gerçekleştirilerek yapının 3B modellemesi yapılmıștır (Alptekin ve ark., 2019b). YLT çok sık nokta verisi sunduğundan rölöve odaklı çalışmalarda da artık yaygın bir şekilde kullanılmaktadır, (Cerit ve Kör, 2020) çalışmlarında Konya Teknik Üniversitesi Sürekli Eğitim Uygulama ve Araştırma Merkezi olarak kullanılan tarihi binanın rölöve projesinin YLT ile hazırlanmasını aktarmışlardır. YLT yönteminin dijital dokümentasyon uygulamalarında doğruluk bakımından yeterliliği (Çelik ve ark., 2020) tarafindan sunulan çalışmada incelenmiş ve yapılan doğruluk analizi neticesinde YLT'nin bu uygulamalarda yeterli olacağı ifade edilmiştir. Bazı durumlarda YLT hedef nesnenin her yerine ulaşamayabilir ki bu durumda eksiklikler ortaya çıkar. $\mathrm{Bu}$ eksiklikleri tamamlamak için fotogrametrik yöntemler kullanılabilir (Xu ve ark., 2016; Ulvi ve ark., 2019).

YLT'ler hedef nesneyi nokta bulutu şeklinde örneklerler. Nokta bulutundaki nokta sayısı hedef nesnenin büyüklüğüne, seçilen tarama parametrelerine ve YLT ile hedef nesne arasındaki tarama mesafesine göre değişiklik gösterse de genellikle milyonlarca noktadan oluşmaktadırlar. YLT'ler hızlı olduklarından ve yüksek hassasiyetli veriler sundukları için özellikle bu alanda çok tercih edilmektedirler.

Tarama neticesinde elde edilen nokta bulutundan 3B yüzey modellemesi, CAD ortamında $2 \mathrm{~B}$ rölöve ölçümleri, 3B çıktı üretmek ve sanal gerçeklik ortamları oluşturmak gibi birçok farklı uygulama yapmak mümkündür.

$\mathrm{Bu}$ çalışmada YLT’nin kültür varlıklarının dijital dokümantasyonunda kullanılabilirliğinin araștırılması ve bütün işlem adımlarını içeren genel bir çerçeve çizilmesi amaçlanmıştır. Bu kapsamda Zonguldak'ın simgelerinden biri olan Uzun Mehmet Anitı YLT ile taranarak elde edilen nokta bulutundan 3B yüzey modeli, CAD çizimleri ve $3 \mathrm{~B}$ çıktı üretilmiştir.

\section{2. ÇALIŞMA ALANI}

Çalışma alanı olarak Zonguldak'ın önemli simgelerinden biri olan Uzun Mehmet Anıtı seçilmiştir. Uzun Mehmet Anıtı, 1973 yılında Cumhuriyet'in 50. yılı anısına Türkiye Taşkömürü Kurumu tarafindan yaptırılmıştır (Kültürportalı 2013). Ayrıca bu anıt Zonguldak Bülent Ecevit Üniversitesi'nin logosunda da kullanılmaktadır.

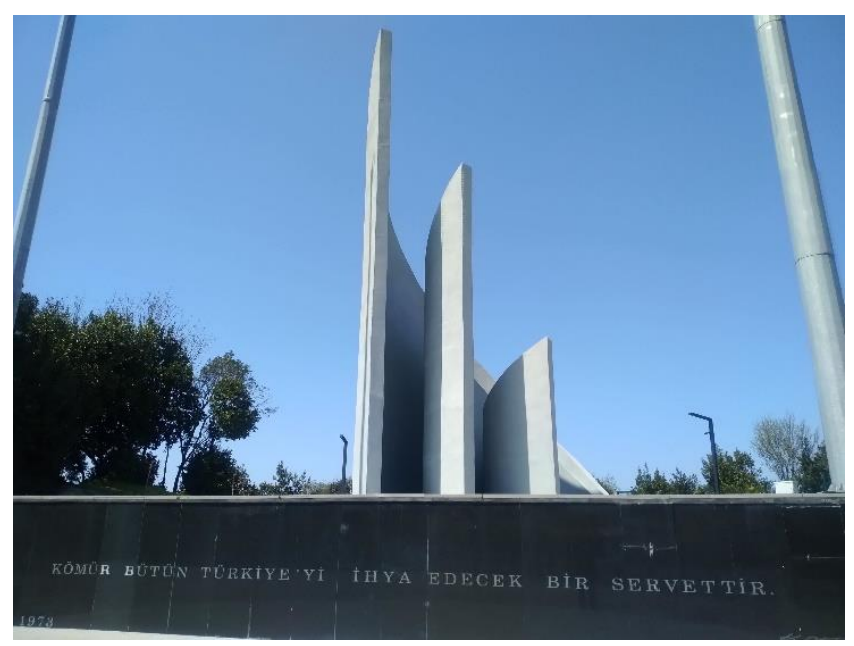

Şekil 1. Zonguldak Uzun Mehmet Anıtı

Anıtın yapıldığı yer Balkaya sırtı olarak adlandırılmaktadır. Bu alana yapılma sebebi ise Zonguldak şehir merkezinin her yerinden görülebilir olmasıdır (Kültürportalı 2013). Anıt inşasından sonra anıt etrafı 1983 yılında Zonguldak Belediyesi tarafindan piknik alanı olarak ilan edilmiştir. Günümüzde ise anıtın bulunduğu arazi Zonguldak Bülent Ecevit Üniversitesi'ne devredilmiştir. Devir işleminden sonra anıtın bulunduğu bölgede çevre düzenlemesi yaplarak 15 Temmuz Şehitler Kampüsü ismi verilmiştir. Ayrıca anıtın dış yüzeyinde bazı dökülmeler olduğu için Zonguldak Bülent 
Ecevit Üniversitesi tarafından gerekli onarım işlemleri yapılmıştır.

\section{YÖNTEM}

YLT'ler küresel koordinat sisteminde çalışırlar ve YLT ile hedef nesne arasındaki mesafeyi $(\rho)$, yatay açıyı $(\theta)$, düsşey açıyı $(\alpha)$ ve hedef nesneden geri yansıyan sinyalin şiddetini ölçerler (Şekil 2).

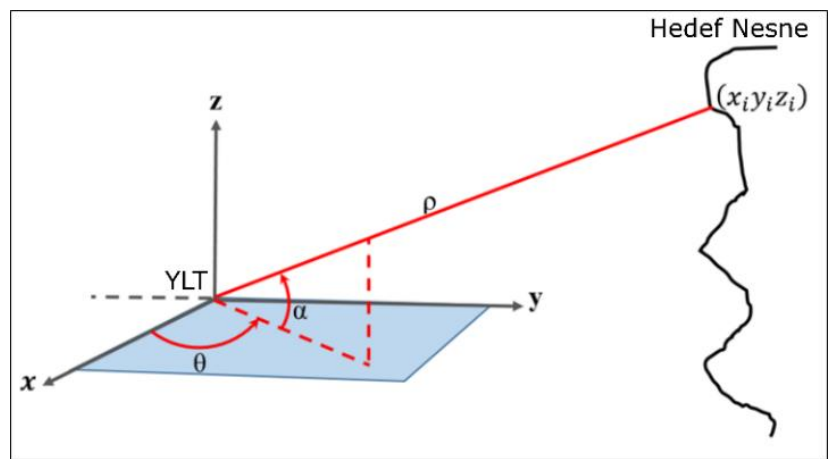

Şekil 2. YLT sistemlerinin yaptığı gözlemler

Hedef nesne ile YLT arasındaki mesafe ölçümü iki farklı prensibe göre yapılmaktadır. Bunlardan birincisinde direkt olarak sinyalin YLT ile hedef nesne arasındaki uçuş zamanını (Time of flight) ölçülürken ikincisinde ise mesafe ölçümünü faz farkının (Phase shift) karşılaştırılması ile gerçekleştirilir(Vosselman ve Maas, 2016).

Birinci yöntemde YLT hedef nesneye atımlar (pulse) gönderir ve lazer kaynağı ile hedef nesne arasındaki uçuş süresini hesaplar. Bu yöntemde YLT ile hedef nesne arasındaki mesafe Eşitlik 1 ile hesaplanabilir (Soudarissanane, 2016).

$\rho=\frac{c \Delta t}{2}$

Eşitlik 1'de $\rho$, YLT ile hedef nesne arasındaki mesafeyi, $c$ ışık hızını ve $\Delta t$ sinyalin seyahat süresini göstermektedir. Faz farkı ile çalışan YLT'ler ise hedef nesneye sürekli dalga (modulated continuous wave) gönderir ve $\Delta t$ Eşitlik 2 ile hesaplanır (Soudarissanane, 2016).

$\Delta t=\frac{\Delta \emptyset}{2 \pi f}$

$\mathrm{Bu}$ eşitlikte $\Delta \emptyset$ faz farkını, $f$ sinüs dalgasının frekansını göstermektedir. Eşitlik 2'deki $\Delta t$ Eşitlik 1'de yerine koyulduğunda Eşitlik 3 elde edilir.

$\rho=\frac{c \Delta \emptyset}{4 \pi f}$

Piyasadaki YLT’lerin çoğu kullanıcıya küresel koordinat sistemindeki $r_{i}=\left[\begin{array}{lll}\rho_{i} & \alpha_{i} & \theta_{i}\end{array}\right]^{T}$ nokta bulutunu vermektense Kartezyen koordinat sistemindeki $\left[\begin{array}{lll}x_{i} & y_{i} & z_{i}\end{array}\right]$ nokta bulutunu verirler (Ozendi ve ark., 2017).

Küresel koordinat sistemindeki herhangi bir $r_{i}=$ $\left[\begin{array}{lll}\rho_{i} & \alpha_{i} & \theta_{i}\end{array}\right]^{T}$ noktasının Kartezyen koordinat sistemine $\left[\begin{array}{lll}x_{i} & y_{i} & z_{i}\end{array}\right]$ dönüşümü Şekil 2'deki geometrik ilişkiler kullanılarak Eşitlik 4 ile yapılabilir (Ozendi ve ark., 2017). $\left[\begin{array}{l}x_{i} \\ y_{i} \\ z_{i}\end{array}\right]=\left[\begin{array}{c}\rho_{i} \cos \left(\alpha_{i}\right) \cos \left(\theta_{i}\right) \\ \rho_{i} \cos \left(\alpha_{i}\right) \sin \left(\theta_{i}\right) \\ \rho_{i} \sin \left(\alpha_{i}\right)\end{array}\right]$

Kartezyen koordinat sisteminden küresel koordinat sistemine de dönüşüm mümkündür. Bu dönüşüm Eşitlik 5 ile verilmiştir.

$$
r_{i}=\left\{\begin{array}{c}
\rho_{i}=\sqrt{x_{i}^{2}+y_{i}^{2}+z_{i}^{2}} \\
\alpha_{i}=\tan ^{-1}\left(\frac{z_{i}^{2}}{\sqrt{x_{i}^{2}+y_{i}^{2}}}\right) \\
\theta_{i}=\tan ^{-1}\left(\frac{y_{i}^{2}}{x_{i}^{2}}\right)
\end{array}\right.
$$

Küresel koordinat sisteminde tanımlı olan düşey açı $(\alpha)$ ve yatay açı $(\theta)$ değerlerinin hesaplanmasında YLT'nin tarama prensibi oldukça önemlidir. Panoramik tarama yapan YLT'ler için Eşitlik 5 ile verilen düşey açı $(\alpha)$ ve yatay açı $(\theta)$ eşitlikleri bu duruma uygun olarak değiştirilmelidir (Lichti, 2010).

YLT'ler konumsal veriye ek olarak her nokta için yoğunluk veya şiddet değerini de (intensity) ölçerler. Yoğunluk değeri genellikle nokta bulutunun görselliğini artırmak için kullanılır (Carrea ve ark., 2016). Özellikle kamera entegresi olmayan YLT verilerinin işlenebilmesi için yoğunluk verisi oldukça kullanışlı olmaktadır. Yoğunluk değeri hedef nesneden geri dönen sinyal miktarının bir ölçüsü olarak tanımlanabilir. Bazı YLT'ler ise yoğunluk değerinin yerine kullanıcıya yansıtım değeri sunarlar. Yansıtım değeri, yoğunluk değerine mesafe ve açı düzeltmelerinin uygulanmış halidir. $\mathrm{Bu}$ işleme literatürde yoğunluk kalibrasyonu (intensity calibraiton) adı verilmektedir (Jaakkola ve ark, 2008; Kaasalainen ve ark., 2008). Kimi YLT'ler kullanıcıya sadece yoğunluk veya yansıtım değerlerinden birini verirken kimi her ikisini de verebilmektedir. Örneğin Faro Focus 3D X330 tarayıcısının nokta bulutu işleme yazılımı olan Faro Scene ekranda yoğunluk değerini gösterirken çıktı olarak sadece yansıtım değerlerini vermektedir. Hedef nesnenin yüzeyinin yansıtıcıllğı ne kadar çoksa yoğunluk değeri o kadar yüksektir. Ayrıca yoğunluk değeri mesafe arttıkça azalır ve lazer ışını ile lokal yüzey normali arasındaki açı ne kadar büyürse o kadar azalır. Bu durum Şekil 3 ile gözlenebilmektedir.

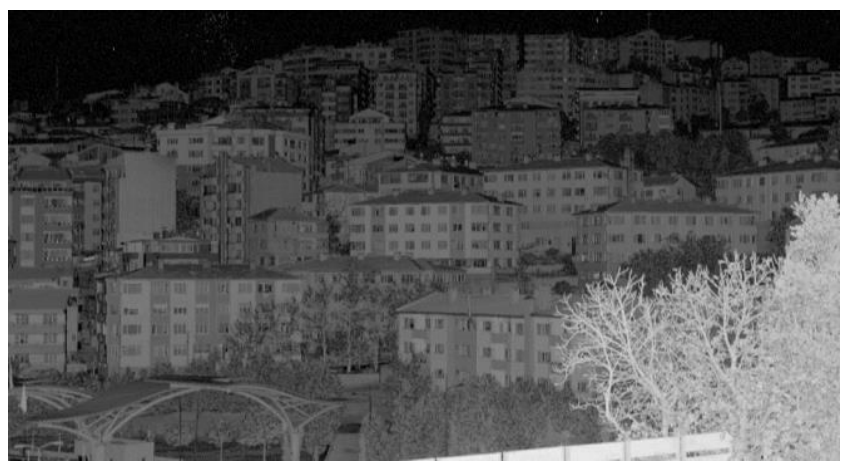

Şekil 3. Faro Focus 3D X330 ile yapılan bir taramanın yoğunluk görüntüsü. Renkler beyaza yaklaştıkça yüzey yansitıcılığı artmakta, siyaha yaklaştıkça yüzey yansıtıcllığı düşmektedir 
$\mathrm{Bu}$ çalışmada faz farkı yöntemi ile çalışan ve panaromik bir tarayıcı olan Faro Focus 3D X330 tarayıcısı kullanılmıștır. Tarayıcının teknik özellikleri Tablo 1'de sunulmuştur.

Tablo 1. Faro Focus 3D X330 tarayıcısının teknik özellikleri

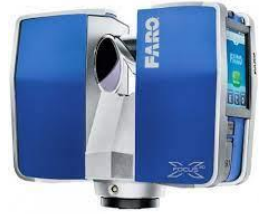

Faro Focus 3D X330

\begin{tabular}{ll}
\hline Lazer Sınıfı & 1 \\
\hline Mesafe Ölçüm Hatası & $\pm 2 \mathrm{~mm}(25 \mathrm{~m}-30 \mathrm{~m})$ \\
\hline Işıı Demeti Uzaklaşımı & $121.0^{\mathrm{cc}}(0.19 \mathrm{mrad})$ \\
\hline Dalga Boyu & $1550 \mathrm{~nm}$ \\
\hline $\begin{array}{l}\text { Açısal Adım Genişliği } \\
\text { (Yatay) }\end{array}$ & $100^{\mathrm{cc}}$ \\
$\begin{array}{l}\text { Açısal Adım Genişliği } \\
\text { (Düssey) }\end{array}$ & $100^{\mathrm{cc}}$ \\
\hline Görüş Alanı (Yatay) & $333.3^{\mathrm{g}}$ \\
\hline Görüş Alanı (Düşey) & $400^{\mathrm{g}}$
\end{tabular}

Faro Focus 3D X330 tarayıcısının ayrica 70 megapixel çözünürlüğünde entegre kamerası vardır. Tarama sırasında bu kamera kullanılırsa elde edilen noktaları kameranın çektiği fotoğraflar ile renklendirmek mümkündür.

$\mathrm{Bu}$ çalışmada kültür varlıklarının YLT yöntemi ile dijital dokümantasyonu için genel bir çerçeve çizilmiştir. $\mathrm{Bu}$ çerçevede veri toplama adımından başlayarak verilerin işlenmesi ve çıtı ürünlerin üretilmesine kadar olan bütün işlem adımları ayrıntılı bir şekilde ele alınmıștır. Sunulan bu çerçevenin iș akıș șeması Șekil 4 ile gösterilmiştir.

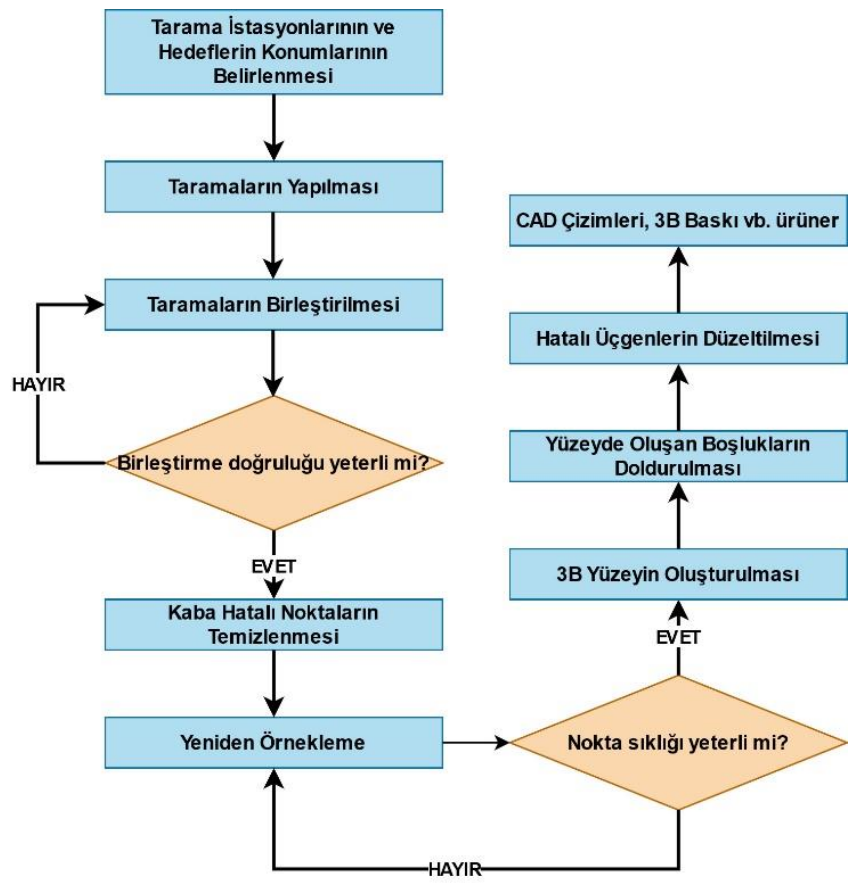

Şekil 4. Dijital dokümantasyon projelerinde iş akış şeması

\subsection{Veri Toplama}

YLT ile yapılacak projelerde planlama büyük önem taşımaktadır. Tarama işlemine başlamadan önce hedef nesnenin eksiksiz bir biçimde her yerinin taranabilmesine olanak sağlayacak şekilde taramanın yapılacağı istasyon noktaları seçilmelidir. Ayrıca nokta bulutlarının birleștirilme aşamasında eğer hedefli birleștirme yöntemi kullanılacaksa istasyon noktalarına ek olarak bir de bu hedeflerin nerelere koyulacağının tarama işleminden önce belirlenmiş olması gerekmektedir.

$\mathrm{Bu}$ çalışma kapsamında Uzun Mehmet Anıtı'nın tümünü kapsayacak șekilde 13 adet tarama gerçekleştirilmiştir. Bu taramalardan iki tanesi anıtın iç kısımlarının da modellenebilmesi için anıtın içinde yapılmıştır ve anıt ile tarayıcı arasındaki mesafe yaklaşık olarak $50 \mathrm{~cm}$ 'dir. Diğer taramalar anıtın etrafında yapılmış olup, en yakın tarama yaklaşık olarak $5 \mathrm{~m}$ mesafeden, en uzak olan tarama ise yaklaşık olarak $9.5 \mathrm{~m}$ mesafeden yapılmıştır. Ortalama olarak tarayıcı ile anıt arasınaki mesafe 8m'dir. Bu taramalar yapilırken tarayıcının çözünürlük parametresi $1 / 4$ kalite parametresi ise $4 \mathrm{x}$ olarak seçilmiștir. Birleștirme işlemi için toplamda 6 adet küresel hedef kullanılmıștır. Sağlıklı bir birleştirme işleminde ardışı taramalar arasında en az üç ortak hedef bulunmalıdır. Küresel hedefler bu şartları sağlayacak șekilde yerleștirilmiștir. Tarama istasyon noktalarının ve küresel hedeflerin konumları Şekil 5'te gösterilmiştir.

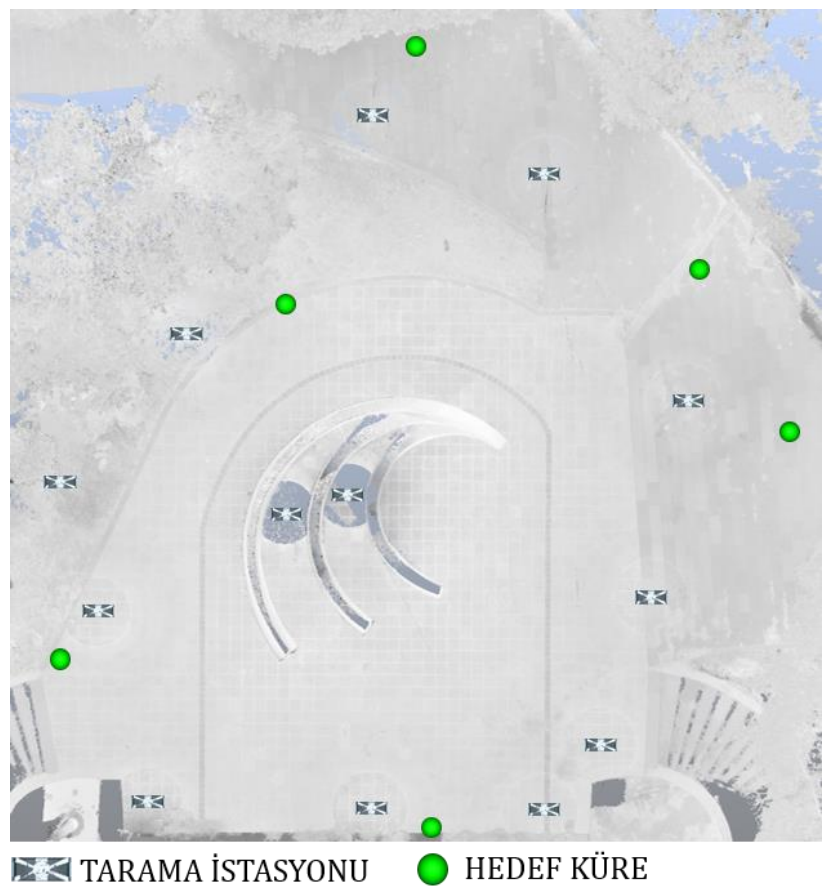

Şekil 5. Çalışma kapsamında tarama yapılan istasyonlar ve hedef kürelerin Uzun Mehmet Anıtına göre konumları (üstten görünüm)

\subsection{Birleștirme}

Taramadan sonraki adım birleștirme ișlemidir. Her tarama farklı bir koordinat sisteminde olduğundan bu nokta bulutunu kullanmak mümkün değildir. Örneğin, Şekil 6(a)'da görüldüğü gibi nesne bütünlüğü yoktur. 
Bunun sebebi her taramanın farklı bir koordinat sisteminde olmasıdır.

$\mathrm{Bu}$ durumu ortadan kaldırmak için birleștirme yapılmalıdır. Birleştirme ișlemi bütün taramaları aynı koordinat sistemine dönüştürmek olarak tanımlanabilir.

Literatürde birleştirme için iki farklı yaklaşım bulunmaktadır. Birinci yöntemde herhangi bir hedefe ihtiyaç duyulmamaktadır. $\mathrm{Bu}$ yöntemde öncelikle taramalar kaba bir şekilde birbirine göre yöneltilir. Yöneltme işlemi otomatik olarak veya kullanıcı yardımı ile yapılabilir. Yöneltmeden sonra taramalar arasındaki hata minimum olana kadar iteratif olarak taramalar yöneltilir (Besl ve McKay, 1992; Gruen ve Akca, 2005).

İkinci yöntemde ise taramaları aynı koordinat sistemine dönüştürmek için hedefler kullanılır. $\mathrm{Bu}$ hedefler farklı markalarda farklılıklar gösterse de prensip olarak farklı taramalarda aynı noktaların seçilmesine imkan sağlarlar. En çok kullanılan hedef türü küresel hedeftir. Yarıçapı belli olan küre tarama verisinde işaretlenir ve matematiksel olarak küre uydurma yapılarak bu kürenin merkez koordinatları hesaplanır. Farklı taramalardaki aynı küre merkez koordinatları kullanılarak 3B rijit dönüşüm parametreleri hesaplanır ve bütün taramalar böylece aynı koordinat sistemine dönüştürülmüș olur (Şekil 6b).

Bu çalışmada taramaları birleştirmek için Faro Scene isimli yazılımın 5.5 versiyonu kullanılmıștır. Küresel hedefler seçildikten sonra birleștirme işlemi yapılmıştır.

Faro Scene 5.5 yazılımın oluşturduğu birleștirme raporuna göre birleștirme işlemi ortalama $\pm 1.65 \mathrm{~mm}$ hata ile gerçekleştirilmiştir. Projedeki noktaların \%85.7'sinin birleștirme hatası $4 \mathrm{~mm}$ değerinin altındadır. Ayrıca taramalar arasındaki bindirme oranı \%55.2 ile \%93 arasında değişmekle birlikte ortalama \%73.7'dir.

\subsection{Hatalı Noktaların Temizlenmesi}

Birleştirmeden sonra yapılması gereken işlem hatalı noktaların temizlenmesidir. Hatalı noktalar genellikle yüzey sürekliliğinin bittiği yerlerde, yansıtım değerinin tarayıcının eşik değerini geçtiği yerlerde ve çok yüksek oranda absorbe edici yüzeylerde oluşmaktadır (Hebert ve Krotkov, 1992; Wang ve ark., 2016). Bu tür hatalı noktalar özellikle faz farkı prensibine göre çalışan YLT’lerde daha çok görülmektedir. 3B yüzey oluşturmadan veya nokta bulutundan CAD çizimleri yapmadan önce bu hatalı noktaların temizlenmesi gerekmektedir. Aksi halde 3B yüzeyde hatalı üçgenler CAD çizimlerinde ise yanlış çizimler yapılacaktır. Şekil 7 'de yüzey sürekliliğinin sona erdiği yerlerde oluşan hatalı noktalar gösterilmiștir.

Hatalı noktaların nokta bulutundan temizlenmesi için nokta işleme yazılımları kullanıcıya bazı algoritmalar sunmaktadırlar. Bu algoritmalar belli bir noktaya kadar başarılı olmalarına rağmen yine de manuel olarak hatalı noktaların temizlenmesi gerekmektedir. Bu çalışma kapsamında hatalı noktaların temizlenmesi için Geomagic Wrap 2015 (3DSystems, 2021) yazılımı kullanılmıştır. Hatalı noktaların temizlenmesi için yazılımın otomatik filtreleme algoritmasına ek olarak kalan hatalı noktalar manuel olarak temizlenmiştir (Şekil 8).

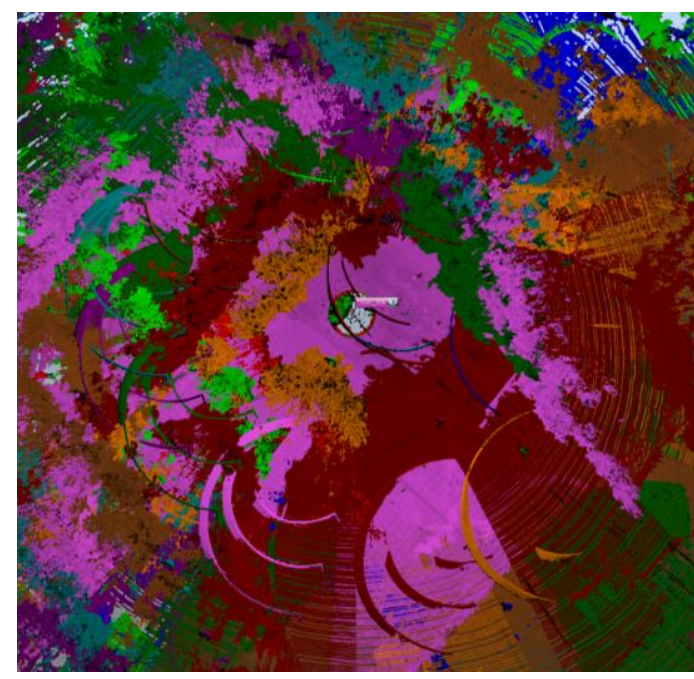

(a) Birleștirmeden önce

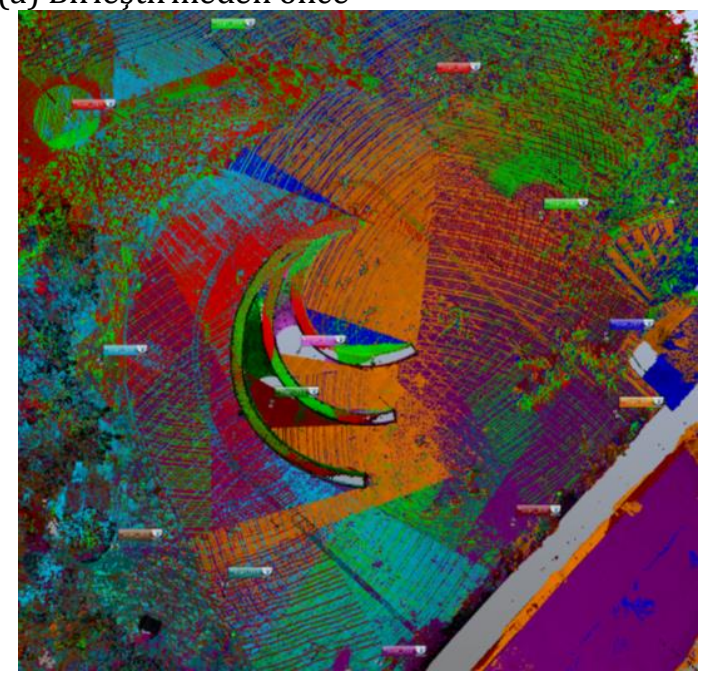

(b) Birleștirmeden sonra

Şekil 6. Her renk bir taramayı göstermektedir. (a) Birleştirmeden önce her tarama farklı bir koordinat sistemindedir. (b) Birleştirmeden sonra bütün taramalar aynı koordinat sistemine dönüştürülmüş ve nesne bütünlüğü sağlanmıştır.

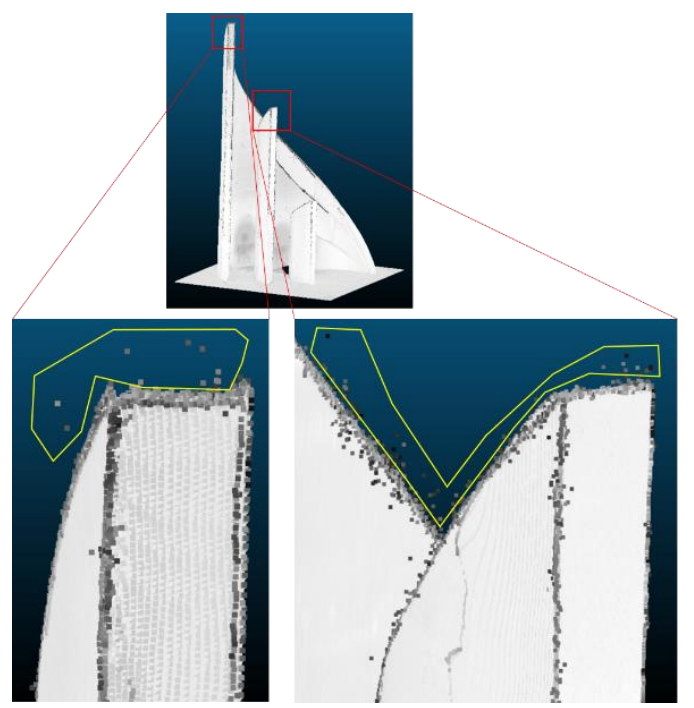

Şekil 7. Yüzey sürekliliğ̈inin bittiği yerlerde oluşan hatalı noktalar (sarı poligon içerisinde) 


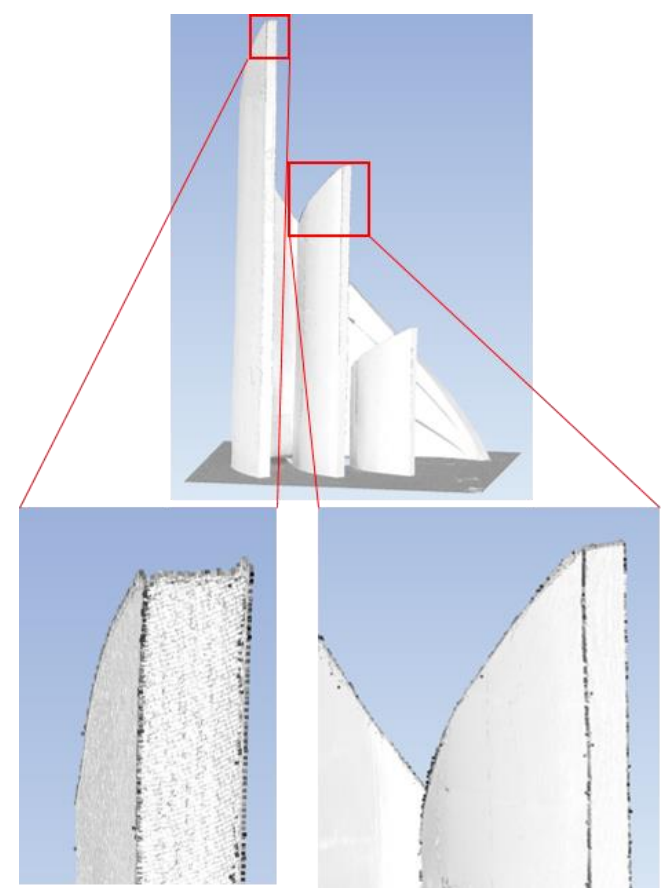

Şekil 8. Hatalı noktalardan arındırılmış nokta bulutu

\subsection{B Yüzey Modeli Oluşturma}

Hatalı noktaları temizlenmiş olan nokta bulutundan 3B yüzey modeli oluşturmak için bu çalışmada Geomagic Wrap 2015 yazılımı kullanılmıştır. 3B yüzey oluşturma işlemine geçmeden önce nokta bulutuna ön işlemler yapılması gerekmektedir. $\mathrm{Bu}$ ön işlemlerden birincisi nokta bulutunu yeniden örneklemektir. Yeniden örnekleme işlemi ile hedef nesneyi temsil eden nokta sayısı azaltılmaktadır. Böylece 3B model oluşturma işleminde daha az sayıda nokta kullanılacağı için hesaplama zamanı kısalacaktır. Farklı yazılımlar kullanıcılara farklı yeniden örnekleme algoritmaları sunmaktadırlar. Bu çalışma kapsmında kullanılan Geomagic Wrap 2015 yazılımında yeniden örnekleme için dört farklı algoritma bulunmaktadır. Birinci algoritmada nokta sayısının belirlenen yüzdesi rastgele olarak silinir. İkinci algoritma eğrilik ve nokta yoğunluğu dikkate almadan eşit aralıklı bir nokta bulutu üretir. Üçüncü algoritma düz yüzeylerde nokta sayısını azaltırken yüksek eğrilikli bölgelerde nokta silmez böylece detaylar korunur. Dördüncü algoritma düz yüzeylerde düzenli bir şekilde nokta sayısını azaltırken eğimli yüzeylerde kullanıcının belirlediği nokta yoğunuğu değerine göre nokta sayısını azaltır.Bu çalışma kapsamında yeniden örnekleme işlemi dördüncü algoritma ile yapılmıştır. Yeniden örnekleme işlemi bütün nesneler için yapılmaz. Eğer modeli üretilecek olan nesne küçük detaylara sahipse (heykel vb.) bu durumda yeniden örnekleme işlemi çok dikkatli yapılmalıdır. Aksi halde 3B yüzey modelinde detay kaybı ortaya çıkar. Bu çalışma kapsamında yeniden örnekleme yapılmasında bir sakınca bulunmamaktadır. Yukarıda bahsedilen yeniden örnekleme algoritmalarından dördüncüsü bu çalışma kapsamında kullanılmıştır. Çünkü modeli üretilecek nesne küçük detaylar içermemekte, eğimli yüzeyleri bulunmakta ve geometrik bir yapıdadır. Yeniden örnekleme sayesinde veri yükü azaltılmış olacak bu da yazılımın işlem süresini azaltacaktır. Hatalı noktalar silindikten sonra elde edilen nokta bulutunda yaklaşık 50 milyon nokta bulunmaktadır. Böyle yoğun bir veriden $3 \mathrm{~B}$ yüzey modeli oluşturmak çok uzun sürecektir. $\mathrm{Bu}$ sebepten dolayı nokta bulutu yeniden örneklenmiştir ve nokta sayısı 2,7 milyona düşürülmüştür (Şekil 9).

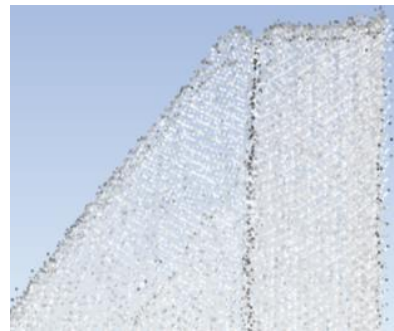

(a)

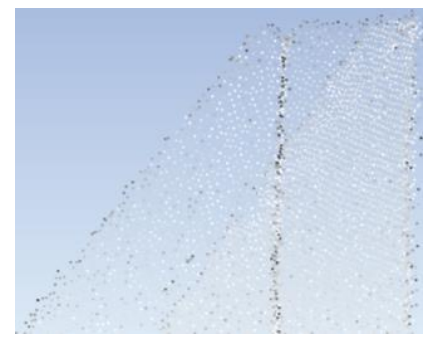

(b)
Şekil 9. Yeniden örnekleme. (a) Yeniden örnekleme öncesi nokta sıklığı (b) Yenden örnekleme sonrası nokta siklığ

Hatalı noktalar temizlendikten ve nokta bulutu yeniden örneklendikten sonra $3 \mathrm{~B}$ yüzey modeli oluşturulmuştur. Geomagic yazılımı 3B yüzey modeli oluşturmak için (Edelsbrunner ve ark., 1998) tarafından geliştirilen algoritmayı kullanmaktadır. Yeniden örneklenen nokta bulutundan elde edilen 3B yüzey modeli Şekil 10 ile gösterilmiştir.

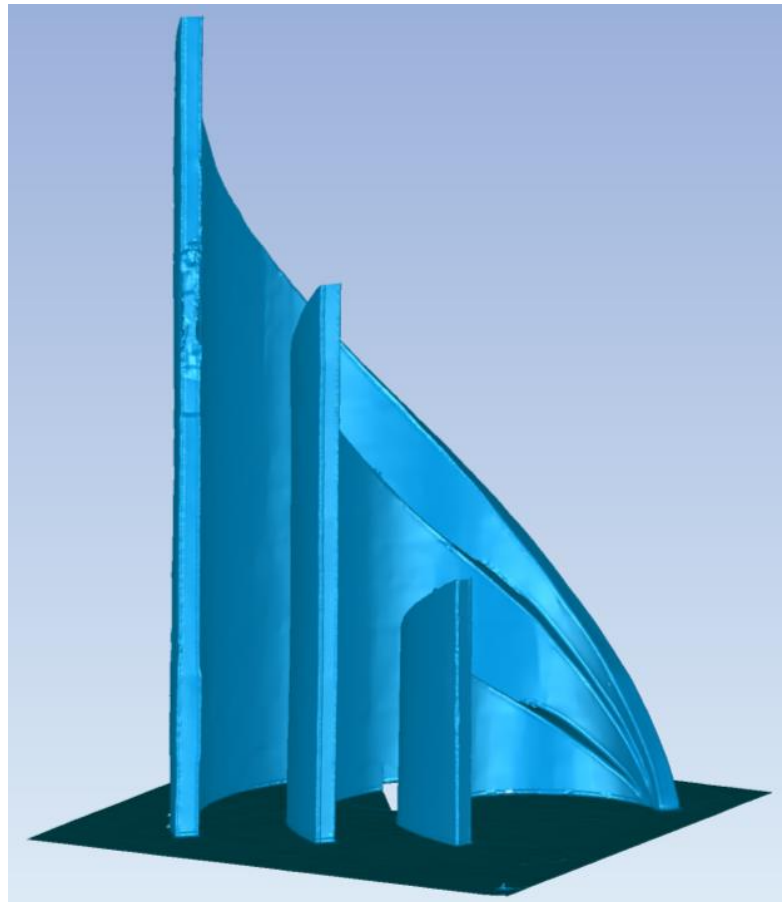

Şekil 10. Yeniden örneklenen nokta bulutundan üretilen $3 B$ yüzey modeli

Üretilen modelde nokta sıklı̆̆ının az olduğu ve üçgenleme yapılamayan yerlerde boşluklar ve bozuk üçgenler oluştuğu Şekil 11'da görülmektedir.

Hedef nesneyi tam olarak modelleyebilmek için bu bozulmaların giderilmesi gerekmektedir. $\mathrm{Bu}$ tür bozulmaları düzeltmek için 3B modelleme yazılımları otomatik ve manuel algoritmalar sunmaktadır. Küçük bozulmaların giderilmesi için otomatik algoritmalar yeterli olurken daha karmaşık ve büyük bozulmalar kullanıcı tarafından manuel olarak düzeltilmelidir. 
$\mathrm{Bu}$ çalışma kapsamında öncelikle 3B yüzey modelindeki bozuk üçgenlerin sebep olduğu sivri uçlu çıkıntılar ve boșluklar manuel olarak giderilmiștir (Șekil 12).

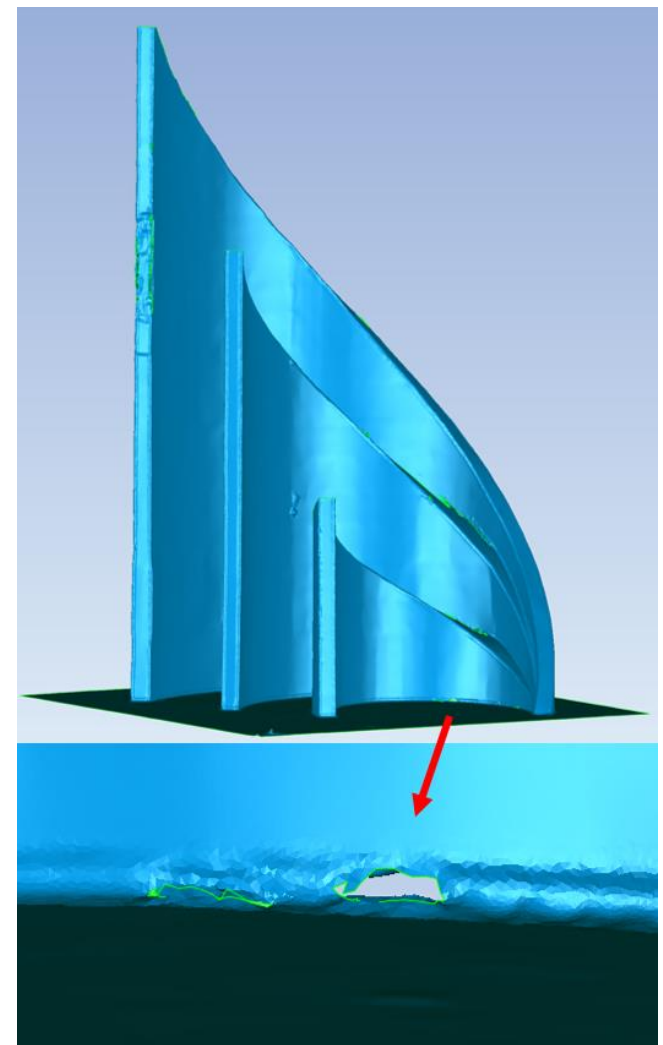

Şekil 11. Bozuk üçgenlerin sebep olduğu bozulmalar ve nokta seyrekliğinden kaynaklanan boșluklar

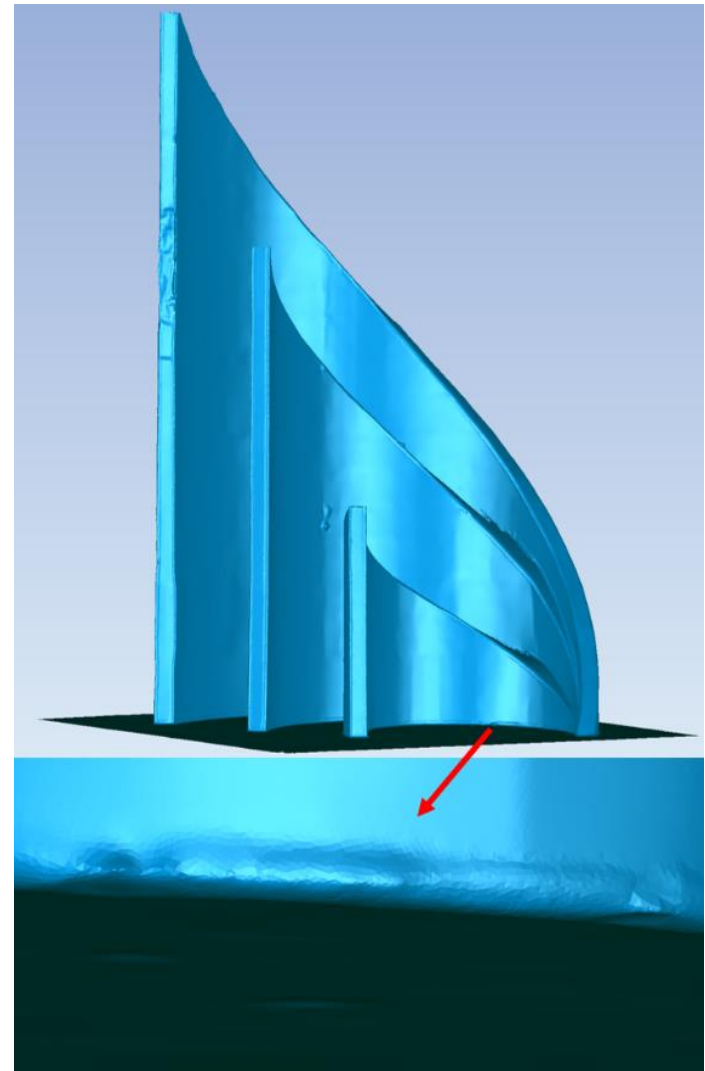

Şekil 12. Bozuk üçgenlerin sebep olduğu bozulmalar ve nokta seyrekliğinden kaynaklanan boşluklar manuel olarak düzeltilmiştir
Üzerinde çalışılan kültür varlığı tek renkli olduğundan çalıșmada elde edilen 3B modele doku verme (texture) işlemi yapılmamıștır. Renk bilgisinin çok önemli olduğu kültür varlıkları söz konusu olduğunda tarayıcıya entegre olan kameranın kullanılmasındansa başka bir profesyonel kamera ile ilgili kültür varlığının fotoğraflarının çekilip doku verme ișlemi yapılması daha uygun olacaktır.

3B yüzey modelinde oluşan bozukluklar giderildikten sonra elde edilen model birçok farklı uygulamada altlık olarak kullanılabilir. En kesit veya boy kesit alma uygulamaları, görsel zenginleștirme, CAD çizimleri, sanal gerçeklik, oyun geliştirme motorları için altlık oluşturma ve 3B yazıcıdan çıktı model üretme bu uygulamaların başlıcalarıdır.

Anıt üzerinde yapılacak onarım çalışmalarında kullanılmak üzere üretilen model üzerinden farklı açılardan bazı CAD çizimleri yapılmıștır. Yapılan CAD çizimlerine ait örnekler Şekil 13'de gösterilmektedir.

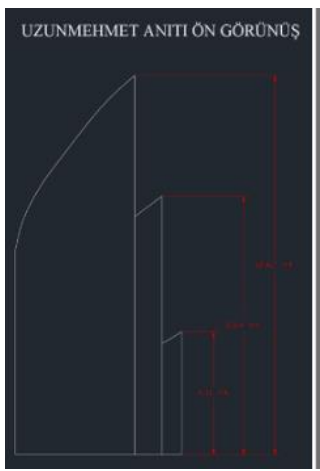

(a)

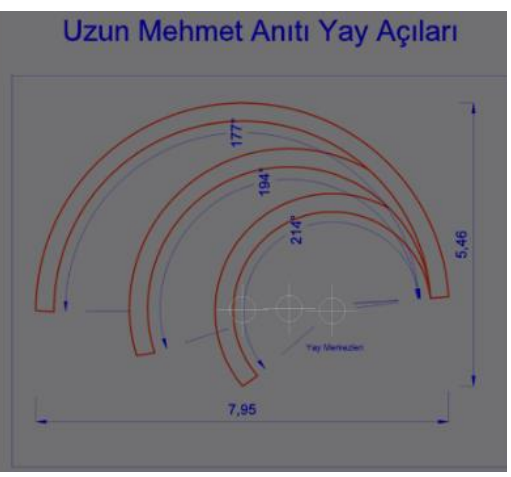

(b)
Uzun Mehmet Anıtı Yay Uzunlukları

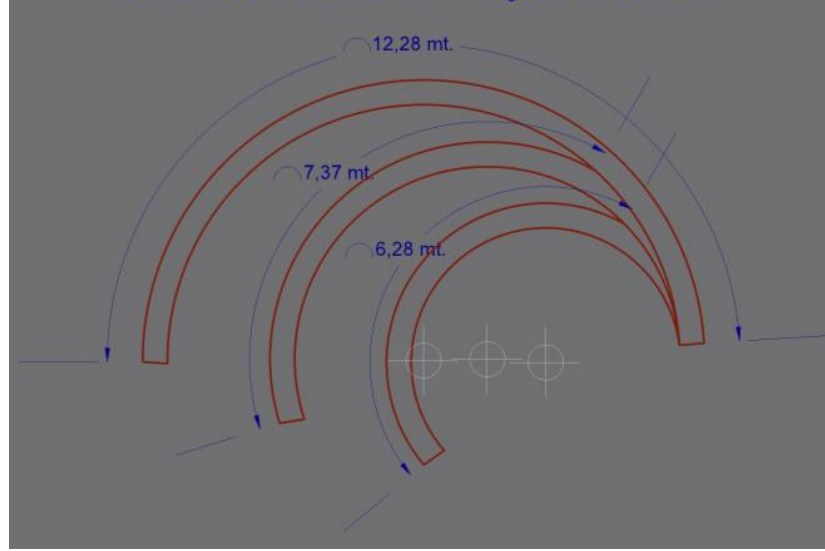

(c)

Şekil 13. 3B yüzey modelinden yapılan CAD çizimleri. (a) Anıtın ön cephe görünümü. (b) Anıtı olușturan yay açlları. (c) Anıt oluşturan yay uzunlukları

\subsection{B Yazıcı Çıktısı}

Günümüzde $3 \mathrm{~B}$ yüzey modellerinden $3 \mathrm{~B}$ yazıcı kullanarak ölçekli gerçek modeller üretmek özellikle tersine mühendislik uygulamalarında oldukça popüler bir hale gelmiştir. Bu çalışma kapsamında Uzun Mehmet Anıtının 3B yüzey modelinden 3B yazıcı kullanılarak gerçek bir modeli de üretilmiștir.

Bu işlem için Zortrax M200 (ZORTRAX, 2021) markalı 3B yazıcı ve aynı firmaya ait olan Z-SUITE yazılımı kullanılmıştır. Kullanılan yazıcı $1,75 \mathrm{~mm}$ çapında 
filament kullanarak model üretmektedir. Boyutları 200x200x180 mm altında olan baskıları 90-100 mikron çözünürlüğünde alabilmekte olup baskı hızı 100 $\mathrm{mm} / \mathrm{sn}^{\prime}$ dir.

Baskı işlemi için üretilen yüzey modelinin STL formatına dönüştürülmesi gerekmektedir. $\mathrm{Bu}$ format dönüşümü için Geomagic Wrap 2015 yazılımı kullanılmıştır. STL formatındaki model ve Z-SUITE yazılımı birlikte kullanılarak baskı parametreleri belirlenmiştir. Bu parametreler baskı kalitesinin ve baskı hızının belirlenmesinde önemli rol oynar. Baskının kalitesini artırmak direkt olarak baskı süresinin uzamasına sebep olmaktadır. Benzer bir şekilde baskının boyutu ne kadar büyük olursa harcanan filaman o kadar çok olacak ve baskı süresi de artacaktır.

Z-SUTIE yazılımında modeli baskıya hazır hale getirmek için yapılacak ilk işlem modelin hangi boyutlarda baskısının alınacağının ayarlanması ve modelin yazıcl tablasina göre pozisyonunun ayarlanmasıdır (Şekil 14). Bir seferde baskısının alınması olanaksız olan büyük modelleri iki veya daha fazla parçaya bölüp parça parça baskısını yapmak da mümkündür.

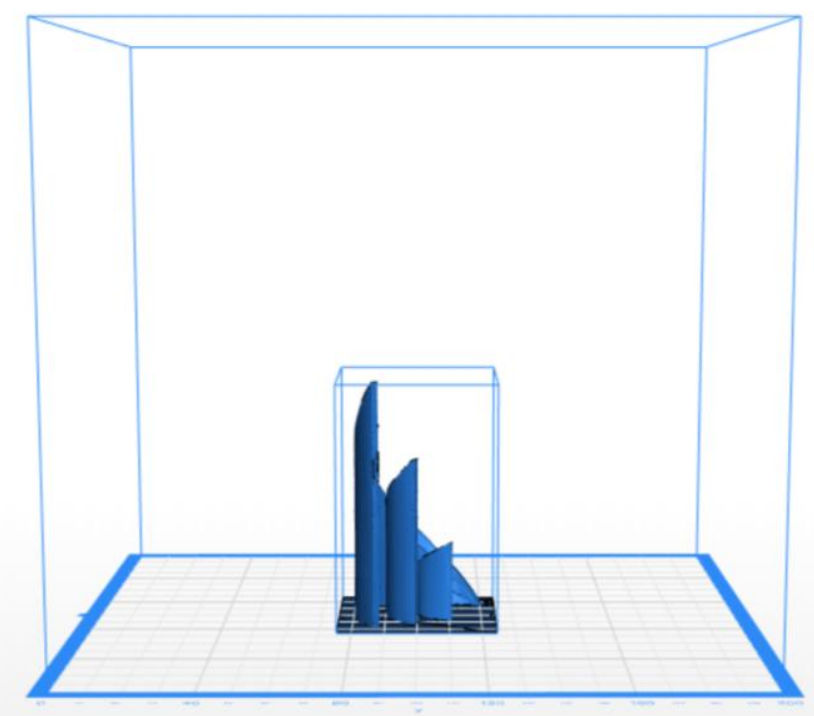

Şekil 14. Dış kısımdaki mavi küp baskı alanını, içerideki mavi küp ise baskının yazıcı tablasına göre konumunu göstermektedir

Sonraki adım ise baskı parametrelerini belirlemektir. Öncelikle hangi tür filamanın kullanılacağ 1 seçilmelidir. Ardından baskının iç boşluklarının nasıl doldurulacağı ayarlanmalıdır. Enjektör ucunun kalınlığı ve baskının hangi kalınlıkta eritilmiş filaman ile yapılacağı ayarlanmalıdır. Bu iki parametreyi baskının çözünürlüğü ve kalitesi olarak düşünmek mümkündür. Kimi modellerin bazı parçaları ile yazıcı tablası arasında boşluk bulunabilmektedir. Bu boşluğun doldurulması gerekir aksi halde baskı devam ederken bu kısımlar yamulup aşağı düşer.

Bahsedilen bu ayarlamalar genel ayarlardır ve birçok farklı 3B yazıcıda bulunmaktadır. Ayarlamalar bittikten sonra baskının önizlemesi yapılıp kontrol edilmelidir (Şekil 15a). Önizleme kontrol edildikten sonra baskı işlemi başlatılabilir.

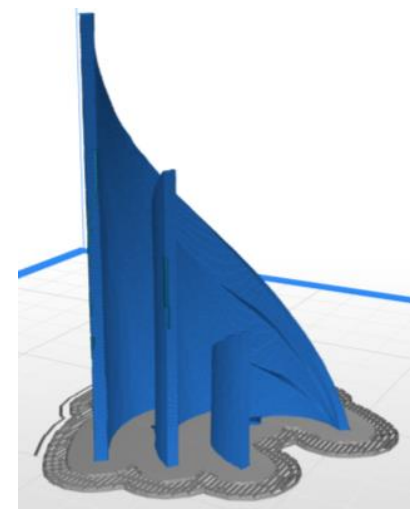

(a)Önizleme

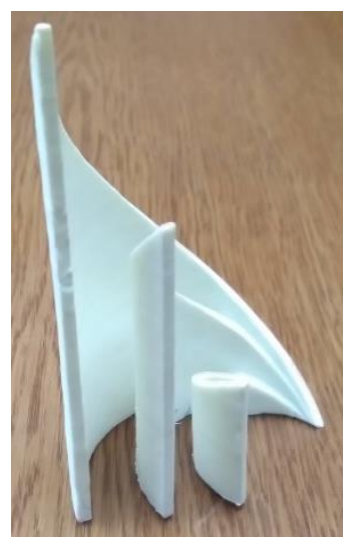

(b)Baskının bitmiş hali
Şekil 15. Modelin 3B yazıcıdaki önizlemesi (a) ve baskının bitmiş hali (b)

\section{BULGULAR}

Çalışma kapsamında Zonguldak'ta bulunan Uzun Mehmet Anıtı'nın dijital dokümantasyonu için Faro Focus 3D X330 YLT ile 13 adet tarama yapılmıștır. Taramaların birleştirilmesi için altı adet küre hedef kullanılmıştır. Her ne kadar altı küre ile proje tamamlanmış olsa da küre sayısını ve kullanılan kürelerin yarıçapını arttırarak arazi çalışması süresi ve veri işleme süreleri düşürülebilecektir. Ayrıca küre hedeflerin sayısının ve yarıçapının arttırılması ile birleștirme işlemi daha hızlı yapılabilir. Daha büyük yarıçaplı küre hedefler kullanıldığında küre uydurma hesaplaması daha uzağa konulan hedefler için de yapilabilecektir. Fakat bu durumu maliyeti ile birlikte değerlendirmek gerekmektedir. Bir diğer alternatif ise yazıcı ile çoğaltılabilen düzlemsel hedefler kullanmaktır.

Taramalar sırasında tarayıcının çözünürlük ve kalite parametreleri $1 / 4 \quad$ ve $4 \mathrm{x}$ olarak seçilmiştir. $\mathrm{Bu}$ parametreler ile elde edilen nokta bulutunda yaklaşık 50 milyon nokta bulunmaktadır. Düzgün geometrisi olan ve üzerinde küçük detayları bulunmayan bu anıtın dokümantasyonu için bu parametrelerin fazla olduğu değerlendirilmiștir. Böyle nesnelerin daha düşük çözünürlük ve kalite parametreleri ile taranması gerekmektedir.

Anit tek renkten oluştuğundan tarama sırasında YLT'nin entegre kamerası kullanılmamıștır. Renk bilgisi önem taşıyan nesnelerin dijital dokümantasyonunda YLT'nin entegre kamerası yerine daha profesyonel bir kamera ile daha kaliteli renk bilgisi ile doku verme işleminin yapılması gerekli olabilir.

Bu tür projelerin en önemli bileşenlerinden biri ofis çalışmasında kullanılan donanımın kapasitesidir. Bu tür projelerde yüksek kapasiteli iş istasyonlarının kullanılması önerilmektedir. Bu çalışmada 64 GB RAM belleği, Intel Xeon CPU E3-1535M v5 işlemcisi ve NVIDIA Quadro M5000M ekran kartı olan mobil iş istasyonu kullanılmıştır.

Anıtın 3B yüzey modelinin üretilmesinde ve modelde ortaya çıkan hataların giderilmesinde Geomagic Wrap 2015 yazılımı kullanılmıştır. Yazılım kullanıcıya oldukça basit bir ara yüz sunduğu ve kolayca 3B yüzey modeli üretimine olanak sağladığı için bu tür projelerde tercih edilebilir. 


\section{SONUÇLAR}

Bu çalıșmada kültür varlıklarının YLT kullanılarak dijital dokümantasyon projesinin başlangıçtan sonuna kadar tüm adımlar ve dikkat edilmesi gereken koşullar Zonguldak'ta bulunan Uzun Mehmet Anıtı örneğinde sunulmuștur.

Anıt 13 farklı istasyondan Faro Focus 3D X330 ile taranmıștır. Birleștirme ișleminde hedef küreler kullanılmış olup, ortalama birleştirme hatası $\pm 1.65 \mathrm{~mm}$ olarak elde edilmiştir. Oluşan kaba hatalı noktaların temizliği yapılmıştır. Nesne düzgün geometrili olduğu için ve küçük detayları olmadığından yeniden örnekleme yapılmıştır. Sonrasında Geomagic Wrap 2015 yazılımı kullanılarak 3B yüzey model oluşturulmuştur. Oluşan 3B yüzey modelindeki boşluklar ve hatalı üçgenler aynı yazılım kullanılarak düzeltilmiştir. Elde edilen bu $3 \mathrm{~B}$ yüzey modelinden CAD çizimleri üretilerek onarım çalışmalarında kullanılmıştır. Ayrıca 3B yazıcı kullanılarak modelin ölçekli gerçek baskısı alınmıştır.

\section{BILLGILLENDİRME/TEŞEKKÜR}

Yazar, bu çalışmaya yardımları dolayısıyla Arş. Gör. Dr. Çağlar BAYIK'a, Harita Yüksek Müh. Ali CAM'a ve Bilgisayar Mühendisi Orhan Yurttaș'a teșekkür eder.

\section{ÇATIŞMA BEYANI}

Herhangi bir çıkar çatışması bulunmamaktadır.

\section{KAYNAKÇA}

3DSystems (2021). Geomagic Wrap 3D Scanning Software.

https://www.3dsystems.com/software/geomagicwrap, Erişim Tarihi 09.03.2021

Aicardi I, Chiabrando F, Maria Lingua A \& Noardo F (2018). Recent trends in cultural heritage 3D survey: The photogrammetric computer vision approach. Journal of Cultural Heritage, 32, 257-266. doi: https://doi.org/10.1016/j.culher.2017.11.006

Akca D (2012). 3d Modeling of cultural heritage objects with a structured light system. Mediterranean Archaeology and Archaeometry, 12, 139.

Alptekin A, Çelik M Ö \& Yakar M (2019). Anıtmezarın yersel lazer tarayıc kullanarak 3B modellenmesi Turkey Lidar Journal, 1(1), 1-4.

Alptekin A, Fidan Ş, Karabacak A, Çelik M Ö \& Yakar M (2019). Üçayak Örenyeri'nin yersel lazer tarayıcı kullanılarak modellenmesi. Turkey Lidar Journal, 1(1), 16-20.

Besl P \& McKay N (1992). A method for Registration of 3D Shapes. IEEE Transactions on Pattern Analysis and Machine Intelligence (PAMI), 14(2), 239 - 256. doi: 10.1109/34.121791

Carrea D, Abellan A, Humair F, Matasci B, Derron M-H \& Jaboyedoff M (2016). Correction of terrestrial LiDAR intensity channel using Oren-Nayar reflectance model: An application to lithological differentiation. ISPRS Journal of Photogrammetry and Remote Sensing, 113, 17-29. doi: 10.1016/j.isprsjprs.2015.12.004
Cerit A T \& Kör M B (2020). Konya Teknik Üniversitesi Sürekli Eğitim Uygulama ve Araștırma Merkezi rölöve projesinin lazer tarama yöntemiyle hazırlanması. Turkey Lidar Journal, 2(1), 10-14.

Çelik M Ö, Hamal S N G \& Yakar İ (2020). Yersel Lazer Tarama (YLT) Yönteminin Kültürel Mirasın Dokümantasyonunda Kullanımı: Alman Çeşmesi Örneği. Türkiye Lidar Dergisi, 2(1), 15-22.

Edelsbrunner H, Facello M A, Fu P, Qian J \& Nekhayev D $\mathrm{V}$ (1998). Wrapping 3D scanning data.

Fryskowska A, Walczykowski P, Deliś P \& Wojtkowska M (2015). ALS and TLS data fusion in cultural heritage documentation and modeling. ISPRS - International Archives of the Photogrammetry, Remote Sensing and Spatial Information Sciences, XL-5/W7, 147-150. doi: 10.5194/isprsarchives-XL-5-W7-147-2015

Gomes L, Bellon O R P \& Silva L (2014). 3D reconstruction methods for digital preservation of cultural heritage: A survey. Pattern Recognition Letters, 50, 3-14. doi: 10.1016/j.patrec.2014.03.023

Gruen A \& Akca D (2005). Least squares 3D surface and curve matching. ISPRS Journal of Photogrammetry and Remote Sensing, 59(3), 151-174. doi: 10.1016/j.isprsjprs.2005.02.006

Hebert M \& Krotkov E (1992). 3D Measurements From Imaging Laser Radars: How Good are They? Image and Vision Computing, 10(3), 170-178. doi: http://dx.doi.org/10.1016/0262-8856(92)90068-E

Jaakkola A, Kaasalainen S, Hyyppä J, Niittymäki H \& Akujärvi A (2008). Intensity Calibration and Imaging with SwissRanger SR-3000 Range Camera. Paper presented at the Proceedings of the ISPRS Congress Beijing 2008.

Junior J D O S, Vrubel A, Bellon O R P \& Silva L (2012). 3D reconstruction of cultural heritages: Challenges and advances on precise mesh integration. Computer Vision and Image Understanding, 116(12), 11951207. doi: 10.1016/j.cviu.2012.08.005

Kaasalainen S, Kukko A, Lindroos T, Litkey P, Kaartinen H, Hyyppa J \& Ahokas E (2008). Brightness Measurements and Calibration With Airborne and Terrestrial Laser Scanners. Geoscience and Remote Sensing, IEEE Transactions on, 46(2), 528-534. doi: 10.1109/TGRS.2007.911366

Kültürportalı 2013. Uzun Mehmet Anıtı - Zonguldak. https://www.kulturportali.gov.tr/turkiye/zongulda k/gezilecekyer/uzun-mehmet-aniti, Erişim Tarihi:09.03.2021

Lichti D D (2010). Terrestrial laser scanner selfcalibration: Correlation sources and their mitigation. ISPRS Journal of Photogrammetry and Remote Sensing, 65(1), 93-102. doi: 10.1016/j.isprsjprs.2009.09.002

Madrigal A C (2019). The Images That Could Help Rebuild Notre-Dame Cathedral https://www.theatlantic.com/technology/archive/2 019/04/laser-scans-could-help-rebuild-notre-damecathedral/587230/, Erişim Tarihi: 09.03.2021

Natura (2019). TARİH GÖBEKLITTEPE İLE YENIDEN YAZILIYOR

http://www.naturadergi.com/anasayfa/tarihgobeklitepe-ile-yeniden-yaziliyor/, Erişim Tarihi:09.03.2021 
Ozendi M, Akca D \& Topan H (2017). A generic point error model for TLS derived point clouds. Paper presented at the SPIE Optical Metrology, Münih / Almanya.

Soudarissanane S (2016). The geometry of terrestrial laser scanning; identification of errors, modeling and mitigation of scanning geometry. Doktora Tezi. TU Delft.

Ulvi A, Yakar M, Yiğit A \& Kaya Y (2019). Arkeolojik Alanlarin Dokümantasyonunun Yersel Lazer Tarama Ve İha Teknikleri İle Elde Edilmesi: Konya Yunuslar Örneği. Paper presented at the TUFUAB X. Teknik Sempozyumu, Aksaray.

Vosselman G \& Maas H G (2011). Airborne and Terrestrial Laser Scanning: Whittles Publishing.

Wang, Q, Sohn H \& Cheng J C P (2016). Development of a mixed pixel filter for improved dimension estimation using AMCW laser scanner. ISPRS Journal of Photogrammetry and Remote Sensing, 119, 246-258. doi: 10.1016/j.isprsjprs.2016.06.004

Xu Z, Wu T H, Shen Y \& Wu L (2016). Three Dimentional Reconstruction of Large Cultural Heritage Objects Based on UAV Video and TLS Data. Int. Arch. Photogramm. Remote Sens. Spatial Inf. Sci., XLI-B5, 985-988. doi: 10.5194/isprs-archives-XLI-B5-9852016

Yağmurlu A (2020). Dünya Mirası ve Kamu Diplomasisi: Göbekli Tepe Örneği. Süleyman Demirel Üniversitesi Fen-Edebiyat Fakültesi Sosyal Bilimler Dergisi, 49, 46-64.

ZORTRAX (2021). Zortrax M200. https://zortrax.com/, Erişim tarihi 21.03.2021

(C) Author(s) 2022. This work is distributed under https://creativecommons.org/licenses/by-sa/4.0/ 